\title{
ADDITION AGENTS IN COPPER ELECTROTYPING SOLUTIONS
}

\author{
By R. O. Hull ${ }^{1}$ and W. Blum
}

\section{ABSTRACT}

The effects of various addition agents in copper electrotyping solutions were investigated. It was found that phenol in the form of phenolsulphonic acid is most satisfactory. Its use permits the electrotypes to be produced in much shorter time, and to be harder than those obtained in ordinary baths.

\section{CONTENTS}

I. Introduction

II. Functions and requirements of addition agents in electrotyping solutions

III. Favorable conditions for operation without addition agents.

1. Composition of the solution

2. Temperature . . .

3. Agitation

4. Current density

5. Time required

IV. Effects of addition agents 770

1. Glue......... 770

2. Dextrin

3. Urea... 770

4. Phenol

V. Plant tests with phenolsulphonic acid. 772

VI. Conclusions................ 773

\section{INTRODUCTION}

Many "addition agents" have been proposed for copper deposition, though comparatively few have been employed on a commercial scale. Of the latter, glue is the best known and is used almost universally in copper refining. In electrotyping, the conditions for copper deposition are quite different from those used in refining. This research ${ }^{2}$ represents a brief survey of the effects of a few typical addition agents in copper electrotyping baths, and the definition of the most favorable operating conditions for baths containing phenolsulphonic acid, which appears to be the most promising of the additions tried.

No attempt will be made in this paper to furnish details for the operation of electrotyping solutions. Such information will be included in a forthcoming revision of Bureau of Standards Circular No. 52.

Research associate, International Association of Electrotypers.

The experimental part of this research was conducted by R. O. Hull, employed as a research associate by the International Association of Electrotypers. 


\section{FUNCTIONS AND REQUIREMENTS OF ADDITION AGENTS IN ELECTROTYPING SOLUTIONS}

In most cases an addition agent is introduced into a depositing bath in order to produce smoother deposits at a given current density, or to permit higher current densities to be used in the production of equally smooth deposits. In electrorefining and electroplating, smoothness of deposits is more important than in electrotyping. Slight roughness on the back of an electrotype shell is actually advantageous, as it leads to better adherence of the type metal used to "back up" the copper.

In general, as the current density is increased, there is a tendency for the deposit to become rougher. A further increase in current density causes the deposit to become "burnt"; that is, dark and spongy. The latter condition may result from a depletion of metal ions in the cathode film or an increase in the $\mathrm{pH}$ of the latter. In either case basic compounds are likely to be included in the deposit. Whether the permissible rate of deposition will be determined by the appearance of roughness or of burning will depend largely on the requirements of the product.

Practical experience and research have shown that higher current densities can be used without causing burning if a high concentration of metal ions is maintained in the cathode film. The factors that favor this condition include $(a)$ a high concentration of the metal salt, in this case copper sulphate, (b) a high temperature, and (c) good agitation. However, these conditions produce relatively soft copper deposits. In actual practice, therefore, the principal purpose of addition agents in electrotyping is to produce harder copper deposits than are obtainable under conditions otherwise favorable for rapid deposition. Addition agents do not as a rule overcome burning of deposits; in fact, in many cases they reduce the limiting current density below that which can be used in similar solutions containing no addition agent.

While meeting the above purpose, it is desirable that an addition agent for use in electrotyping should not need close control, as electrotyping is usually carried out in relatively small plants, without the aid of chemical analysis. It is therefore preferable to use a substance that is effective over a wide range of concentrations and that does not require frequent replenishment. The cost of the addition agent is less significant than in refining, which is carried out on a much larger scale.

\section{FAVORABLE CONDITIONS FCR OPERATION WITHOUT ADDITION AGENTS}

As noted above, the principal function of addition agents in electrotyping is to counteract the tendency to produce soft copper deposits under the conditions that are otherwise favorable for rapid deposition. The first part of this investigation involved a brief study of the conditions for rapid copper deposition from solutions containing only copper sulphate and sulphuric acid.

The chief function of the copper sulphate is to furnish the metal ions required for deposition. The sulphuric acid greatly increases the conductivity, an effect which is especially important when high-current 
densities must be obtained with a limited voltage. (Most generators used in electroplating and electrotyping furnish current at 6 volts. Generators with two commutators will supply current at 12 volts with, however, a corresponding decrease in their current capacity.) In addition, the sulphuric acid reduces anode polarization and thereby increases the anode efficiency. It also retards the formation of burnt deposits.

On general principles it might, therefore, be assumed that the concentrations of both copper sulphate and sulphuric acid should be made as high as possible. But the addition of sulphuric acid reduces the solubility of copper sulphate; hence it is necessary to select the combination which most nearly meets the requirements of metal and hydrogen ion concentration and conductivity.

In determining the optimum conditions of deposition, the copper was deposited upon thin sheet lead (about 10 by $15 \mathrm{~cm}$ or 4 by 6 inches) that had been treated with a dilute chromate solution to permit subsequent separation of the copper sheets. The lead was held in a hard rubber frame and so placed in a glass battery jar that both the current density and the agitation were nearly uniform over the entire cathode surface. The agitation was produced between the anode and cathode by introducing air through small holes in a glass tube. The rolled copper anode had approximately the same area as the cathode and was placed about $10 \mathrm{~cm}$ ( 4 inches) from the latter. The temperature was kept within $1^{\circ} \mathrm{C}$. of that desired, by immersing the vessel in a water bath at an appropriate temperature.

Numerous experiments, of which the details are unimportant, showed that fairly smooth but soft copper deposits can be obtained rapidly under conditions such as the following:

\section{COMPOSITION OF THE SOLUTION}

\begin{tabular}{|c|c|c|c|}
\hline - & $\begin{array}{l}\text { Approxi- } \\
\text { mately } \\
\text { normal }\end{array}$ & $\mathrm{g} / \mathrm{l}$ & $\begin{array}{l}\text { A voir- } \\
\text { dupois } \\
\text { oz./gal. }\end{array}$ \\
\hline $\begin{array}{l}\text { Copper sulphate, } \mathrm{CuSO}_{4} \cdot 5 \mathrm{H}_{2} \mathrm{O} \\
\text { Sulphuric acid, } \mathrm{H}_{2} \mathrm{SO}_{4}\end{array}$ & $\begin{array}{l}2 \\
1.5\end{array}$ & $\begin{array}{r}250 \\
75\end{array}$ & $\begin{array}{l}33 \\
10\end{array}$ \\
\hline
\end{tabular}

\section{TEMPERATURE}

$40^{\circ} \mathrm{C}$. or $104^{\circ} \mathrm{F}$. (This is about the maximum temperature that can be safely used without softening the wax molds employed in electrotyping.)

\section{AGITATION}

As good and as uniform as can be produced by introducing air through suitable pipes.

\section{CURRENT DENSITY}

Under these conditions, a current density of $25 \mathrm{amp} / \mathrm{dm}^{2}$ (230 amp/ $\mathrm{ft}^{2}$ ) can be used. This generally requires in practice a potential of at least 6 volts at the tank. When this is not available, or when the agitation is not the best, the current density may have to be reduced, for example, to $15 \mathrm{amp} / \mathrm{dm}^{2}$ or $140 \mathrm{amp} / \mathrm{ft}^{2}{ }^{2}$ 


\section{TIME REQUIRED}

The deposition of the ordinary electrotype shell with an average thicknes of $0.15 \mathrm{~mm}$ or 0.006 inches requires about 13 ampere-hours per $\mathrm{dm}^{2}$ or 120 ampere-hours per square foot. At the maximum current density suggested above, about one-half hour will be required to deposit the shell, and a correspondingly longer time when lower current densities are employed. When no addition agents are present, it is customary in commercial plants to use a current density of only about $7 \mathrm{amp} / \mathrm{dm}^{2}\left(65 \mathrm{amp} / \mathrm{ft}^{2}\right)$ and to take about two hours for the deposition. If, therefore, by means of addition agents, suitably hard deposits can be produced in a shorter time, it will be a great advantage, especially in periods of peak production, or for rush orders.

\section{EFFECTS OF ADDITION AGENTS}

Preliminary tests were made in a bath of the above composition with several typical additions that have been used or suggested for copper baths, including glue, dextrin, urea, and phenol. These produced the following effects.

\section{GLUE}

Glue had the most marked effect of any addition agent tried. Under the most favorable conditions with high current densities it produced very smooth, hard deposits. The optimum concentration was found to be about $10 \mathrm{mg} / \mathrm{l}(0.0013 \mathrm{oz} . / \mathrm{gal}$.$) , which is over three$ times the concentration commonly used in copper refining, in which there is no air agitation and in which a relatively low current density is employed (about $2 \mathrm{amp} / \mathrm{dm}^{2}$ or $19 \mathrm{amp} / \mathrm{ft}^{2}{ }^{2}$ ). The concentration of glue must be kept within fairly close limits to be effective. A smaller concentration than the above has very little effect at these ligh current densities, while a much higher content of glue leads to the production of brittle deposits. There is no method of determining this small content of glue by analysis. Its estimation by measuring the polarization, as suggested by H. E. Haring ${ }^{3}$ for copper refining baths, is not applicable, as the maximum polarization is reached with about $10 \mathrm{mg} / \mathrm{l}$ of glue. Although glue is being employed successfully in a few electrotyping plants, it is not well suited for this purpose.

\section{DEXTRIN}

Dextrin in a concentration of $1 \mathrm{~g} / 1(0.13 \mathrm{oz} . / \mathrm{gal}$. $)$ produced deposits that were only slightly smoother than those from plain solutions. When the concentration was increased to $10 \mathrm{~g} / \mathrm{l}(1.3 \mathrm{oz} . / \mathrm{gal}$.) the deposits were very smooth, but relatively soft. There was no increase in hardness of the deposits produced after continued electrolysis. Dextrin appears to have no special advantage to warrant its use in electrotyping.

\section{UREA}

A solution containing about $1 \mathrm{~g} / \mathrm{l}(0.13 \mathrm{oz} . / \mathrm{g}$ al. $)$ of urea first yielded a deposit that was smooth, but soft and coarsely crystalline. After electrolysis for several hours the deposit then produced was hard and fine grained. It is evident that any effectiveness of urea as an addi- 
tion agent depends upon the formation from it of some substance of different properties. No attempt was made to identify this secondary product, as it in turn was apparently unstable. Within a few days the solution ceased to yield smooth or hard deposits. Similar results were obtained with a solution containing about $5 \mathrm{~g} / \mathrm{l}(0.67 \mathrm{oz} . / \mathrm{gal}$.) of urea. While urea has been used to some extent commercially, it requires frequent replenishment and is not, therefore, especially suitable for electrotyping.

\section{PHENOL}

When phenol ( $1 \mathrm{~g} / \mathrm{l}$ or $0.13 \mathrm{oz} . / \mathrm{gal}$.) was added directly to the solution, the deposit first produced was very soft and coarsely crystalline. When the electrolysis was continued for several hours, the deposits then produced were smooth, hard, and fine grained. Here again, it was evident that some product formed from the phenol was more effective than the phenol itself. The most obvious assumption was that the phenol had reacted slowly with the sulphuric acid to form phenolsulphonic acid. Upon this assumption the latter compound was prepared by heating equal volumes of phenol and concentrated sulphuric acid to $100^{\circ} \mathrm{C}$. $\left(212^{\circ} \mathrm{F}\right.$.) for one hour. The product was then introduced into a fresh solution in the amount necessary to yield the same concentration of phenol as was used above. Smooth, hard deposits were then obtained in the first electrolysis. This result indicated that it was preferable to add the phenol as phenolsulphonic acid in order to immediately get beneficial results. Another advantage in using the combined phenol is that in this form it is less readily volatilized from the agitated solution. Such volatilization causes a loss of phenol and also a disagreeable odor.

Continued tests with solutions containing phenolsulphonic acid showed that while an immediate beneficial effect was observed, the maximum effect was not obtained until after electrolysis for a few days. During this period the solution acquired a dark-green color, evidently produced by an optical combination of the blue of copper sulphate and some yellow or brown compound formed during electrolysis.

Because the solutions are agitated with air, conditions are favorable for the oxidation of any organic compounds that may be present. Among the products of oxidation of phenol are hydroquinol and quinone. Attempts to jdentify either of these compounds in the used solutions were not conclusive. However, when one of these substances was substituted for the phenolsulphonic acid the solution soon darkened and yielded smooth, hard deposits. It is probable that one (or both) of these compounds is formed in the solution to which phenolsulphonic acid has been added, and thus accounts for at least part of the observed effect.

If so, it might be added instead of the phenolsulphonic acid. Hydroquinol is relatively cheap and its use might be warranted in order to avoid the trouble and inconvenience of preparing the phenolsulphonic acid. It was subsequently tried in a few plant tests, but for some reason it did not yield as satisfactory results as did the phenolsulphonic acid. Quinone is relatively expensive, and its commercial use is probably not justified. A few experiments indicated that if the hydroquinol is first treated with acidified dichromate to oxidize it to quinone and the resulting solution is added to the bath, favorable results are obtained. 


\section{PLANT TESTS WITH PHENOLSULPHONIC ACID}

As the laboratory experiments showed that phenolsulphonic acid is useful over a fairly wide range of concentration and that its effects are quite lasting, tests were made with it in several commercial electrotyping plants. These tests showed that by its use hard, smooth copper deposits can be produced without special precautions at much higher current densities than can otherwise be employed. In connection with these tests, analyses of the solutions were made at intervals in order to determine the rate of depletion of the phenolsulphonic acid and the effects of such depletion.

The result of the analysis was expressed as the total phenol equivalent. This included free phenol, that combined as the sulphonic acid, and any hydroquinol or quinone formed in the bath. The method for determining phenol depends upon the fact that free bromine combines with phenol or its sulphonic acid to form tribromphenol

$$
\mathrm{C}_{6} \mathrm{H}_{5} \mathrm{OH}+3 \mathrm{Br}_{2}=. \mathrm{C}_{6} \mathrm{H}_{2} \mathrm{Br}_{3} \mathrm{OH}+3 \mathrm{HBr}
$$

Under similar conditions hydroquinol and quinone probably form bromine addition compounds. If these substances are present in considerable amount, the analytical result, expressed as "equivalent phenol," is only a rough guide to the total concentration of addition agent present.

The method was applied to the analysis of the copper bath as follows. Dilute a $10 \mathrm{ml}$ sample of the solution to $50 \mathrm{ml}$ and add $2 \mathrm{~g}$ of 20 -mesh granulated zinc to precipitate the copper. When the copper is all removed, filter the solution into a $200 \mathrm{ml}$ flask, and add $10 \mathrm{ml}$ of a $0.1 N$ "bromine solution" and $50 \mathrm{ml}$ of concentrated hydrochloric acid. (The bromine solution contains $2.8 \mathrm{~g} / \mathrm{l}$ of potassium bromate, and $12 \mathrm{~g} / \mathrm{l}$ of potassium bromide. It is standardized against $0.1 \mathrm{~N}$ thiosulphate under the same conditions as are used for the determination.) Close the flask with a rubber stopper, and heat it in a water bath to $50^{\circ} \mathrm{C}$. for one-half hour. Cool, add $2 \mathrm{ml}$ of a 10 per cent solution of potassium iodide, shake well, and titrate the liberated iodine (using starch indicator) with $0.1 N$ thiosulphate, which has been similarly standardized against $0.1 \mathrm{~N}$ dichromate $\left(4.9 \mathrm{~g} / \mathrm{I}_{2} \mathrm{Cr}_{2} \mathrm{O}_{7}\right)$. From the volumes of thiosulphate used in this titration and in the standardization of the bromine solution, the phenol equivalent of the solution may be calculated. One $\mathrm{ml}$ of $0.1 \mathrm{~N}$ bromine solution is equivalent to $0.00157 \mathrm{~g}$ of phenol.

Tests in several plants showed that after an initial rapid decrease the average depletion of phenol became less than 1 per cent per day. Decidedly beneficial results were obtained in one bath over a period of nearly six months, at the end of which period the deposits began to be soft and rough. During this time the equivalent phenol concentration, as determined by the above method, decreased from 1.0 $\mathrm{g} / \mathrm{l}$ to $0.1 \mathrm{~g} / \mathrm{l}$. An addition of phenolsulphonic acid was then made to bring the concentration back to $1.0 \mathrm{~g} / 1$, and the deposits immediately became smooth and hard. 


\section{CONCLUSIONS}

While phenolsulphonic acid produces no beneficial effects upon the character of the copper deposits that might not be obtained with other addition agents in appropriate concentration, it appears better adapted to electrotyping than other substances. It is effective over a wide range of concentration and its effects (or those caused by products derived from it) persist over a long period of operation. The following conditions will probably be satisfactory for most electrotyping plants.

\section{Suggested operating conditions}

1. Solution-

Copper sulphate, $\mathrm{CuSO}_{4} .5 \mathrm{H}_{2} \mathrm{O}$

Sulphuric acid, $\mathrm{H}_{2} \mathrm{SO}_{4}$

Phenol (introduced as phenolsulphonic acid)

Averdupois $\mathrm{g} / 1$ oz./gal.

$250 \quad 33$

$75 \quad 10$

0. 13

2. Temperature- $35^{\circ}$ to $40^{\circ} \mathrm{C}$. $\left(95^{\circ}\right.$ to $104^{\circ} \mathrm{F}$.).

3. Current Density-

1. With very good agitation amp/dm²

2. With fair agitation or at lower temperature

The authors are indebted to N. Bekkedahl, who succeeded R. O. Hull as research associate and completed the plant tests and analyses; also to the officers and members of the International Association of Electrotypers for their cooperation and advice, especially in the plant tests.

Washington, May 1, 1930. 